Please note this manuscript is a non-peer reviewed EarthArXiv preprint and has not formally been accepted for publication.

Submitted Manuscript: Confidential

\title{
Title: Global fast-traveling tsunamis by atmospheric pressure waves on the 2022 Tonga eruption
}

\author{
Authors: Tatsuya Kubota ${ }^{1 *}$, Tatsuhiko Saito ${ }^{1}$, Kiwamu Nishida ${ }^{2}$
}

\author{
Affiliations: \\ ${ }^{1}$ National Research Institute for Earth Science and Disaster Resilience; Tsukuba, 305-0006, \\ Ibaraki, Japan. \\ ${ }^{2}$ Earthquake Research Institute, the University of Tokyo; Tokyo, 113-0032, Tokyo, Japan \\ *Corresponding author. Email: kubotatsu@bosai.go.jp
}

10 Abstract: On January 15, 2022, the Hunga Tonga-Hunga Ha'apai volcano erupted, causing tsunamis all around the world; enigmatic tsunamis arrived much earlier by $>\sim 2 \mathrm{hr}$ than the conventionally predicted tsunami travel time. Here, we investigated the generation and propagation mechanisms of the tsunami "forerunner." The simulation found that fast-moving atmospheric pressure waves drove the leading sea height rise, while the scattering of the leading waves by small islands in the Pacific Ocean triggered the coda tsunamis. The tsunamis arriving later than the theoretically predicted time are composed of various waves generated both from traveling and static sources, which makes the tsunami much more complex and longer-lasting than earthquake-induced tsunamis.

One-Sentence Summary: We discovered the generation mechanisms of the fast-traveling tsunamis by atmospheric pressure waves on the 2022 Tonga eruption.

\section{Main Text:}

At 04:14:45 on January 15, 2022 (UTC), a massive volcanic eruption occurred on a small, uninhabited island in the South Pacific, Hunga Tonga-Hunga Ha'apai (black triangle in Fig. 1A) (1). This volcano stretches $20 \mathrm{~km}$ across and is topped by a submarine caldera $5 \mathrm{~km}$ in diameter (2). Satellite-based observations revealed that this eruption blasted volcanic ash into the 
Please note this manuscript is a non-peer reviewed EarthArXiv preprint and has not formally been accepted for publication.

Submitted Manuscript: Confidential

stratosphere as high as $\sim 40 \mathrm{~km}$ and most parts of the island disappeared (2-4). The atmospheric pressure rises with amplitudes of $\sim 2 \mathrm{hPa}$ propagated globally, as observed by the world barograph network (Fig. 1B). The satellite-based observations captured this global atmospheric pressure wave propagation $(4,5)$. The initial waves propagating at a velocity of $\sim 300 \mathrm{~m} / \mathrm{s}$ are Lamb waves, atmospheric pressure waves propagating in the air at the acoustic speed $(6,7)$. Similar global pressure waves have also been recorded in past volcanic eruptions $(8-10)$.

Global coastal tide gauges recorded tsunamis associated with this eruption (4) (fig. S1), but they arrived much earlier by $>\sim 2-3 \mathrm{~h}$ than the theoretically predicted tsunami travel time from the volcano, $T_{\text {tsun }}$ (green contour lines in Fig. 1A) (5). The globally distributed oceanbottom pressure gauges also recorded these fast-traveling tsunamis, with amplitudes of $\sim 3-4 \mathrm{hPa}$ at the time corresponding to the Lamb wave arrivals, as well as the subsequent tsunami-like disturbances (Fig. 1C). Compared to past major earthquake-induced tsunamis, the ocean-bottom pressure changes due to this eruption were much longer in duration (fig. S2). Here, we investigated the generation mechanism of these enigmatic global forerunning and long-lasting tsunamis, related to the atmospheric pressure waves radiated by the eruption. 
Please note this manuscript is a non-peer reviewed EarthArXiv preprint and has not formally been accepted for publication.

Submitted Manuscript: Confidential
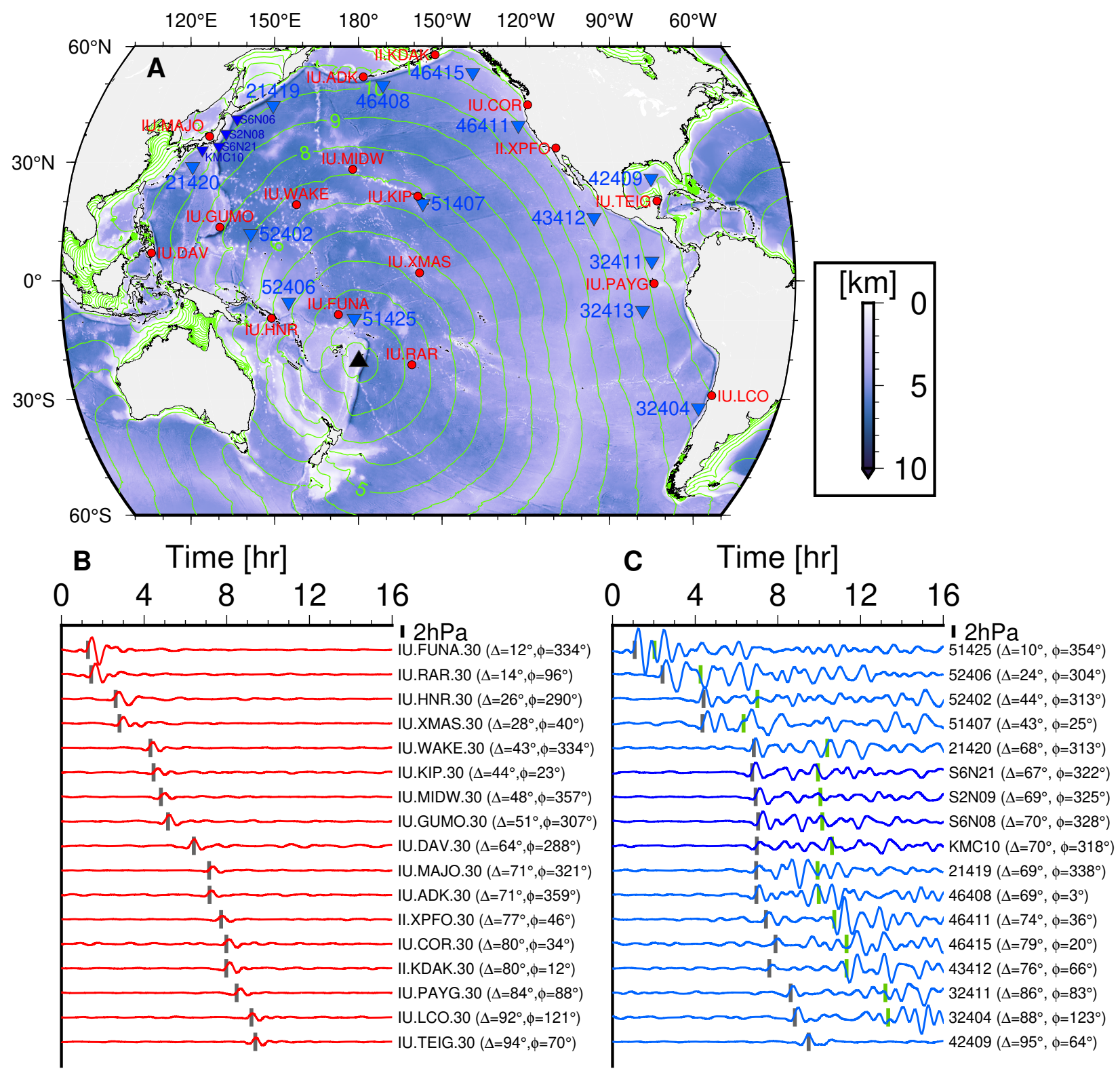

Fig. 1. Location map and observation dataset. A. Location map. The black triangle denotes the Hunga Tonga-Hunga Ha'apai. Red circles denote the barographs. Blue inverted triangles are the ocean bottom pressure gauges. Green contour lines are the theoretical tsunami travel time, $T_{\text {tsun. }}$ B. Observed barograms. C. Observed ocean-bottom pressure gauge waveforms. The angular distances between the source and stations $(\Delta)$ and the azimuth from the source to the station $(\varphi)$ are also shown. A bandpass filter with a passband of 1,800-7,200 was applied. The theoretical travel times of the Lamb wave $\left(\Delta / V_{0}\right.$, gray bars) and tsunami (green bars) are also shown. 
Please note this manuscript is a non-peer reviewed EarthArXiv preprint and has not formally been accepted for publication.

Submitted Manuscript: Confidential

We studied a tsunami propagating across the globe generated by the Lamb wave. The methods are detailed in the Supplementary Material. Assuming the Lamb wave at a propagation velocity of $V_{0}=300 \mathrm{~m} / \mathrm{s}$ (Fig. 1B), we first conducted a global propagation simulation of atmospheric pressure waves (Fig. 2A). We then simulated the generation and propagation of ocean waves driven by the atmospheric pressure waves $(11,12)$ using global bathymetry data (13). We finally calculated the ocean-bottom pressure changes $\left(p_{\text {bot }}\right)$ as the sum of the atmospheric pressure $\left(p_{\text {atm }}\right)$ and the sea-surface height changes $\eta\left(p_{\text {eta }}=\rho_{\mathrm{w}} g_{0} \eta, \rho_{\mathrm{w}}\right.$ : seawater density, $g_{0}$ : gravity acceleration, $\left.9.8 \mathrm{~m} / \mathrm{s}^{2}\right): p_{\text {bot }}=p_{\text {atm }}+p_{\text {eta }}(12,14)$.

The observed and simulated waveforms of the barographs and ocean-bottom pressure gauges are compared in Fig. 2 and fig. S3. These waveforms coincided well with each other around Lamb wave arrivals. After some additional simulations assuming various $V_{0}$ values, we found that the observed tsunamis were reproduced with velocities of $V_{0}=280-320 \mathrm{~m} / \mathrm{s}$ (fig. S4).

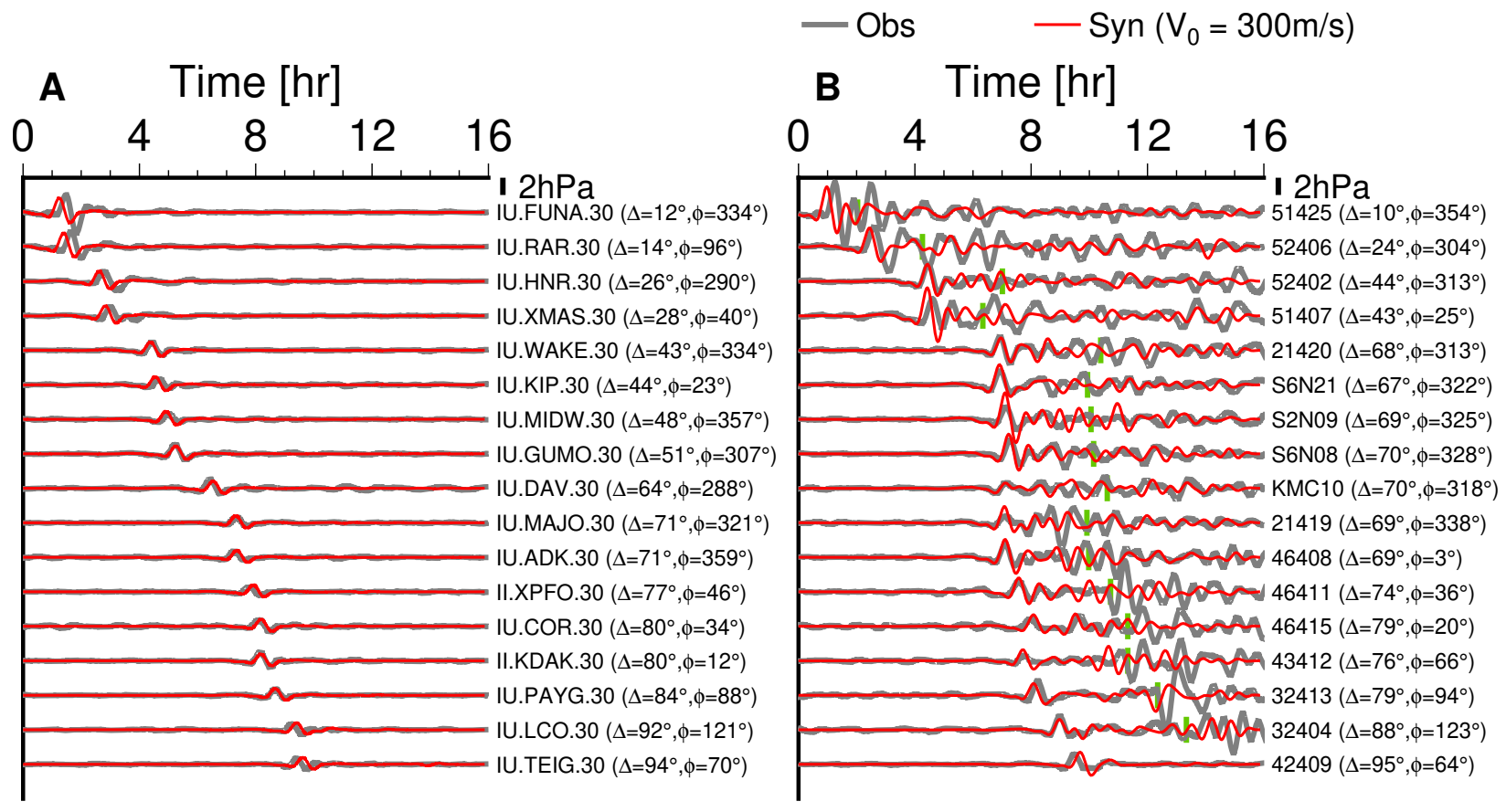

Fig. 2. Comparisons between the observed and simulated waveforms. A. Comparison for the barograph waveforms. B. Comparison for the ocean-bottom pressure waveforms. Gray and red traces are the observed and simulated waveforms. The waveform traces are aligned based on the azimuthal distance from the source. The theoretical travel times of the tsunami (green bars) are also shown. 
Please note this manuscript is a non-peer reviewed EarthArXiv preprint and has not formally been accepted for publication.

Submitted Manuscript: Confidential

The global propagation of atmospheric pressure and fast-traveling tsunami is shown in Movie S1 and Fig. 3. In association with the propagation of the $\sim 2 \mathrm{hPa}$ atmospheric waves (Fig. 3A), we can confirm the propagation of the leading sea-surface uplift (red arrows in Fig. 3B), which is interpreted as the waves forcibly excited by the Lamb waves. We also found that the $\sim 4$ $\mathrm{hPa}$ forerunning ocean-bottom pressure increases corresponding to the Lamb wave pulse (Fig. 3C). The relative amplitude ratio between the atmospheric and ocean-bottom pressures was consistent with global observations (Fig. 1). It should be noted that this wave was not generated by a resonant mechanism between tsunamis and atmospheric waves (15) because the sea surface height did not increase with an increase in travel distance. On careful inspection of some regions such as the Hawaiian Islands, the South Pacific Islands, and the Mariana Trench, scattered tsunamis are generated by these islands and steep bathymetry changes, as secondary sources (black arrows in Fig. 3B). A simulation assuming fully flat ocean earth, which did not excite these secondary waves, confirmed that the bathymetry-related scattering was the cause of these tsunamis following the leading wave (figs. S5 and S6).

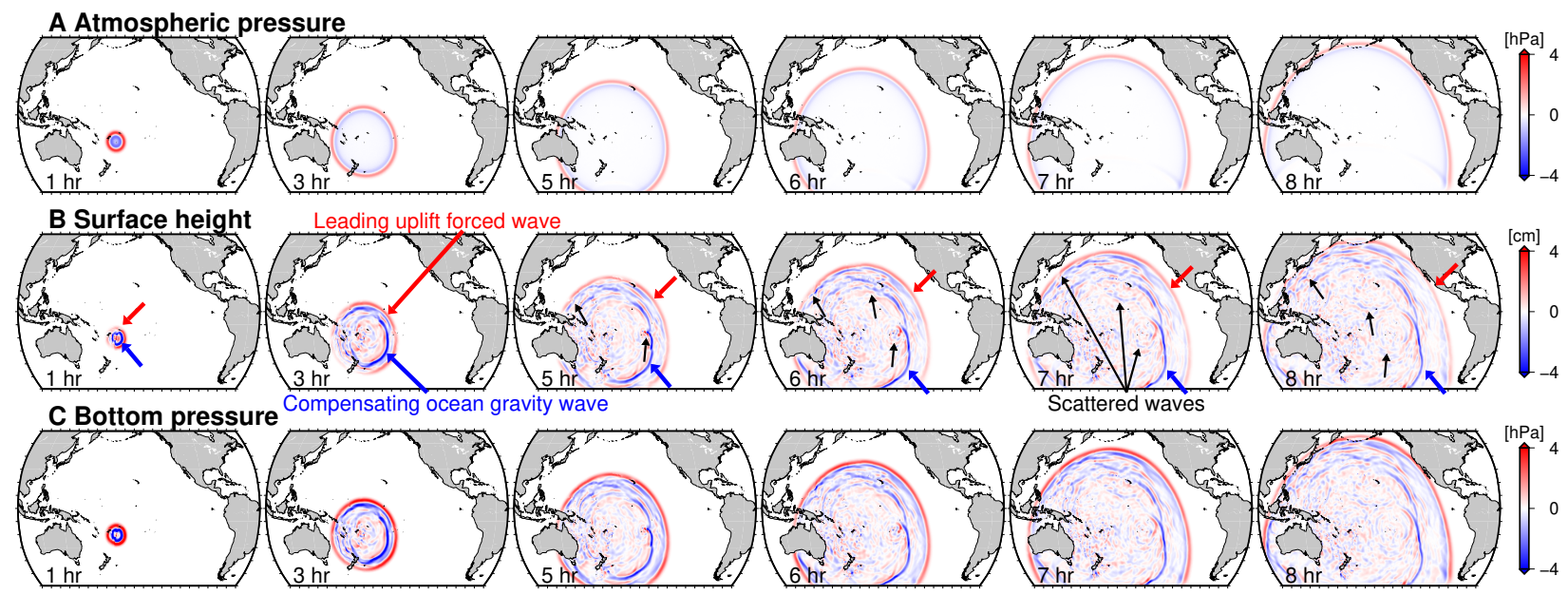

Fig. 3. Snapshots of the generation and propagation of tsunamis. A. Snapshots of the atmospheric pressure wave, B. Snapshots of the sea-surface height change. Distinct wave signals are marked by arrows. C. Snapshots of the ocean-bottom pressure change. The animation of this simulation is available in Movie S1. 
Please note this manuscript is a non-peer reviewed EarthArXiv preprint and has not formally been accepted for publication.

Submitted Manuscript: Confidential

After passing the Lamb-wave pulse and the scattering-originated tsunamis, the propagation of the sea-surface depression can also be confirmed (blue arrows in Fig. 3B), in which its wavefront spreads at the theoretically predicted tsunami velocity $c_{0}=\left(g_{0} h_{0}\right)^{0.5}\left(g_{0}\right.$ : gravity acceleration, $h_{0}$ : seawater depth). This wave is expected to be a result of water volume conservation $(14,15)$ (fig. S7, Movie S2). The sea surface uplift forcibly caused by the Lamb waves propagates around at a velocity of $V_{0}$, which causes sea-surface subsidence at the source to conserve the total water volume. The subsided sea-surface displacement then collapses due to gravity and propagates as tsunamis at velocity $c_{0}$. This subsidence wave is one of the factors consisting of tsunamis after the theoretical tsunami arrival, $T_{\text {tsun }}$ (component $2 \mathrm{~A}$ in Fig.4).

Tsunamis generated at the volcano source region by seafloor crustal deformation due to eruptions $(16,17)$ or volcano collapses $(18,19)$ can also contribute to tsunamis after $T_{\text {tsun }}$ (component 2C). Another important factor is the waves caused by atmospheric pressure waves propagating at a velocity close to tsunamis $\left(V_{0} \sim \mathcal{c}_{0}\right.$, component $\left.2 \mathrm{~B}\right)(11,15)$, as the volcanic eruption excites various atmospheric waves other than Lamb waves (10). Some of them are

15 referred to as atmospheric gravity wave modes, which have a velocity close to that of a tsunami $(\sim 200-220 \mathrm{~m} / \mathrm{s})$ for most parts of the Pacific Ocean $\left(h_{0} \sim 4-5 \mathrm{~km}\right)$. This results in the resonance of the waves $(15,20-23)$, in which the atmosphere continuously supplies the wave energy to the ocean and thus the tsunami height increases with the increase in travel distance. All the waves excited by the mechanisms of components $2 \mathrm{~A}, 2 \mathrm{~B}$, and $2 \mathrm{C}$ in Fig. 4 propagate at a velocity of $c_{0}$ $\sim 200-220 \mathrm{~m} / \mathrm{s}$ as tsunamis.

To appropriately reproduce the entire observed tsunami waveforms, it is essential to consider all the contributing factors shown in Fig. 4 (components 1, 2A, 2B, and 2C). Components $2 \mathrm{~A}$ and $2 \mathrm{C}$ can be reproduced by the framework of the conventional tsunami simulation because they propagate at the tsunami velocity $c_{0}$ and the source can be regarded as

25 static. If the seafloor is completely flat, the amplitudes of these waves decay with the propagation distance, in proportion to $r^{-1 / 2}$ ( $r$ : propagation distance, figs. S8 and S9). On the other hand, in component $2 \mathrm{~B}$, the wave amplitude increases at a rate proportional to $r^{1 / 2}$ when the resonance occurs between the ocean wave and moving source (figs. S8 and S9). This indicates that the contribution by the atmospheric gravity waves (component $2 \mathrm{~B}$ ) can be larger after 30 propagating a certain distance than the others. We can confirm the amplification feature in the tide gauge records at some locations such as the South American coast (fig. S1). 
Please note this manuscript is a non-peer reviewed EarthArXiv preprint and has not formally been accepted for publication.

Submitted Manuscript: Confidential

\section{Atmospheric pressure}

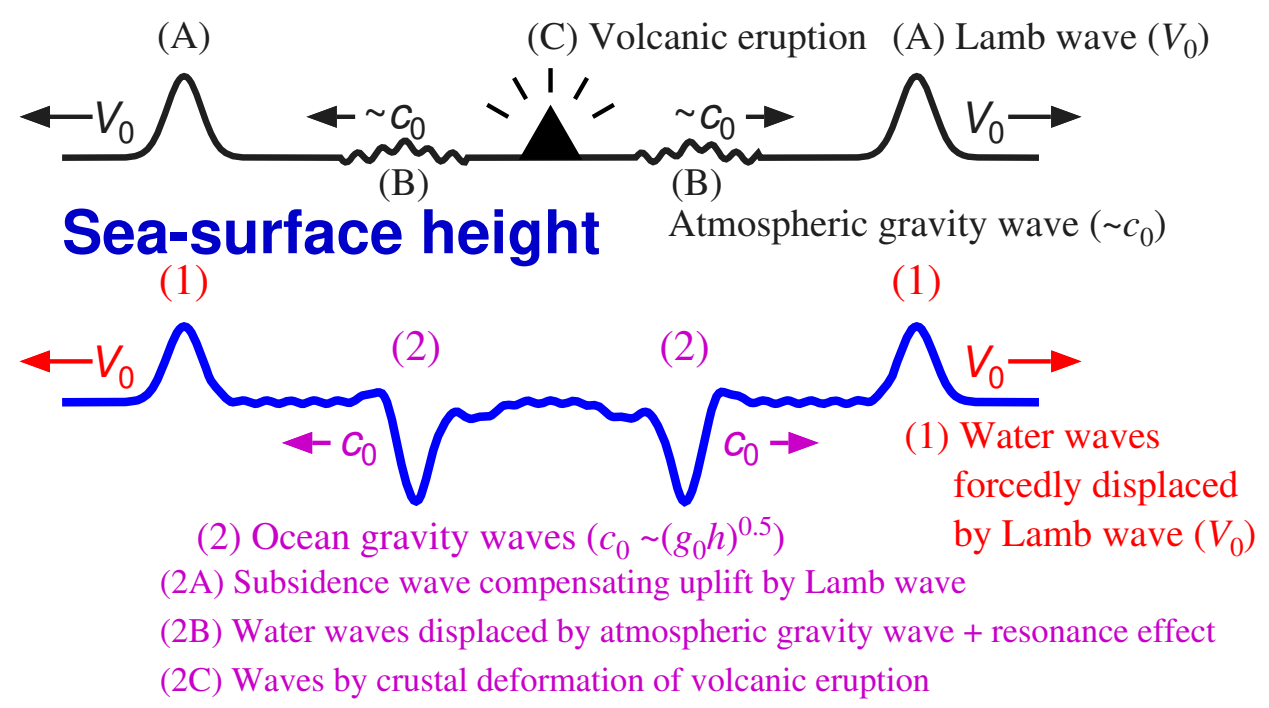

Fig. 4. Schematic illustration of the generation mechanism of the tsunamis in the 2022 Tonga eruption event.

The characteristics of the tsunami generation by volcanic eruptions, as studied here, make global tsunami warning more challenging than earthquake-induced tsunamis. The first challenge is the warning for the tsunami forerunner produced by Lamb waves' forced oscillation. Because the pressure change at the ocean's bottom caused by this leading wave is a superposition of the pressure changes caused by the Lamb wave and tsunamis, $p_{\text {bot }}=p_{\text {atm }}+p_{\text {eta }}(12,14)$, the ocean-bottom pressure does not directly represent the tsunami height, whereas the coastal tide gauges observe only the sea height changes but not the atmospheric pressure. This makes it difficult to accurately calculate the tsunami height from global ocean-bottom pressure gauges. We must consider the effect of the atmospheric pressure rise on the bottom pressure changes to conduct the precise forecast of the global tsunami forerunner $(24,25)$. Another critical issue for tsunami warning is tsunamis excited by atmospheric gravity waves. The atmospheric gravity waves radiated by the eruption amplify the tsunamis with the increase in propagation distance. Even if the amplitudes of the gravity waves are weak, tsunamis are continuously amplified 
Please note this manuscript is a non-peer reviewed EarthArXiv preprint and has not formally been accepted for publication.

Submitted Manuscript: Confidential

throughout the propagation, which will enlarge the wave amplitude at a greater distance than the near-source region, as well as making its duration much longer than the ordinary earthquakeinduced ones, even for several days (fig. S2). There are some factors to control the amplitudes these global tsunamis, such as the radiation directivity of tsunamis by the source crustal

5 deformation, the amplitudes and directivity of the radiated Lamb and atmospheric gravity waves (9), and the advection effect during the propagation related to the jet stream at stratospheric heights $(7,26,27)$. The most decisive factor in controlling the global tsunami size and duration is the amount how much gravity wave modes $(\sim 200 \mathrm{~m} / \mathrm{s})$ are excited by the eruption. To forecast the long-lasting resonant-induced tsunamis precisely, we need to accurately model the generation and propagation of gravity wave modes. In the aftermath of disastrous tsunamigenic earthquakes such as Sumatra and Tohoku, our global-scale evaluations of tsunami risks and hazards were developed. The present analyses of the 2022 Tonga tsunami shed light on the importance of new global tsunami risk evaluations from volcanic eruptions, as well as the importance of establishing a new science of global tsunamis (28).

\section{References and Notes}

1. U.S. Geological Survey, (USGS), "M 5.8 Volcanic Eruption - 68 km NNW of Nuku'alofa, Tonga" (2022, https://earthquake.usgs.gov/earthquakes/eventpage/us7000gc8r/executive).

2. National Aeronautics and Space Administration, (NASA), "Dramatic changes at Hunga Tonga-Hunga Ha“apai” (2022, https://earthobservatory.nasa.gov/images/149367/dramaticchanges-at-hunga-tonga-hunga-haapai).

3. NASA, "Hunga Tonga-Hunga Ha'apai erupts" (2022, https://earthobservatory.nasa.gov/images/149347/hunga-tonga-hunga-haapai-erupts).

4. J. Duncombe, The surprising reach of Tonga's giant atmospheric waves, Eos 103 (2022). doi:10.1029/2022EO220050.

5. R. G. Andrews, "Tonga shock wave created tsunamis in two different oceans" (2022, https://doi.org/10.1126/science.ada0562).

6. H. Lamb, Hydrodynamics (Dover, Mineola, New York, ed. 6, 1932).

7. K. Nishida, N. Kobayashi, Y. Fukao, Background Lamb waves in the earth's atmosphere. 
Please note this manuscript is a non-peer reviewed EarthArXiv preprint and has not formally been accepted for publication.

Submitted Manuscript: Confidential

8. R. H. Scott, I. Note on $\mathrm{n}$ a series of barometrical disturbances which passed over Europe between the 27th and the 31st of August, 1883. Proc. R. Soc. Lond. 36, 139-143 (1883).

9. T. Mikumo, B. A. Bolt, Excitation mechanism of atmospheric pressure waves from the 1980 Mount St Helens eruption. Geophys. J. R. Astron. Soc. 81, 445-461 (1985). doi:10.1111/j.1365-246X.1985.tb06412.x

10. H. Kanamori, J. Mori, D. G. Harkrider, Excitation of atmospheric oscillations by volcanic eruptions. J. Geophys. Res. 99, 21947-21961 (1994). doi:10.1029/94JB01475.

11. J. R. Garrett, A theory of the Krakatoa tide gauge disturbances. Tellus. 22, 43-52 (1970). doi:10.3402/tellusa.v22i1.10157

12. T. Kubota, T. Saito, N. Y. Chikasada, O. Sandanbata, Meteotsunami observed by the deepocean seafloor pressure gauge network off northeastern Japan. Geophys. Res. Lett. $\mathbf{4 8}$, e2021GL094255 (2021). doi:10.1029/2021GL094255.

13. C. Amante, B. W. Eakins, "ETOPO1 1 arc-minute global relief model: procedures, data sources and analysis" (NOAA Tech. Memo. NESDIS NGDC-24, National Geophysical Data

15 Center, National Oceanic and Atmospheric Administration, 2009; https://www.ngdc.noaa.gov/mgg/global/relief/ETOPO1/docs/ETOPO1.pdf).

14. T. Saito, T. Kubota, N. Y. Chikasada, Y. Tanaka, O. Sandanbata, Meteorological tsunami generation due to sea-surface pressure change: Three-dimensional theory and synthetics of ocean-bottom pressure change. J. Geophys. Res. Oceans 126, e2020JC017011 (2021). doi:10.1029/2020JC017011.

15. J. Proudman, The effects on the sea of changes in atmospheric pressure. Geophys. Suppl. Mon. Not. R. Astron. Soc. 2, 197-209 (1929). doi:10.1111/j.1365-246X.1929.tb05408.x

16. B. H. Choi, E. Pelinovsky, K. O. Kim, J. S. Lee, Simulation of the trans-oceanic tsunami propagation due to the 1883 Krakatau volcanic eruption. Nat. Hazards Earth Syst. Sci. 3, 321-332 (2003). doi:10.5194/nhess-3-321-2003

17. R. Paris, A. D. Switzer, M. Belousova, A. Belousov, B. Ontowirjo, P. L. Whelley, M. Ulvrova, Volcanic tsunami: a review of source mechanisms, past events and hazards in Southeast Asia (Indonesia, Philippines, Papua New Guinea). Nat. Hazards 70, 447-470 (2014). doi:10.1007/s11069-013-0822-8

18. S. T. Grilli, D. R. Tappin, S. Carey, S. F. L. Watt, S. N. Ward, A. R. Grilli, S. L. Engwell, C. Zhang, J. T. Kirby, L. Schambach, M. Muin, Modeling of the tsunami from the December 
Please note this manuscript is a non-peer reviewed EarthArXiv preprint and has not formally been accepted for publication.

Submitted Manuscript: Confidential

22, 2018 lateral collapse of Anak Krakatau volcano in the Sunda Straits, Indonesia. Sci. Rep. 9, 11946 (2019). doi:10.1038/s41598-019-48327-6

19. R. Williams, P. Rowley, M. C. Garthwaite, Reconstructing the Anak Krakatau flank collapse that caused the December 2018 Indonesian tsunami. Geology 47, 973-976 (2019). doi: $10.1130 / \mathrm{G} 46517.1$

20. M. Ewing, F. Press, Tide-gage disturbances from the great eruption of Krakatoa. Trans. Am. Gephys. Union 36, 53-60 (1955). doi:10.1029/TR036i001p00053

21. F. Press, D. Harkrider, Air-sea waves from the explosion of Krakatoa. Science 154, 1325 1327 (1966). doi:10.1126/science.154.3754.1325

22. D. Harkrider, F. Press, The Krakatoa air-Sea waves: an example of pulse propagation in coupled systems. Geophys. J. R. Astron. Soc. 13, 149-159 (1967). doi:10.1111/j.1365246X.1967.tb02150.x

23. P. W. Francis, The origin of the 1883 Krakatau tsunamis. J. Volcanol. Geotherm. Res. 25, 349-363 (1985). doi:10.1016/0377-0273(85)90021-6

24. V. V. Titov, F. I. González, E. N. Bernard, M. C. Eble, H. O. Mofjeld, J. C. Newman, A. J. Venturato, Real-time tsunami forecasting: Challenges and solutions. Nat. Hazards 35, 35-41 (2005). doi:10.1007/s11069-004-2403-3

25. E. Bernard, V. Titov, Evolution of tsunami warning systems and products. Phil. Trans. R. Soc. A 373, 20140371 (2015). doi:10.1098/rsta.2014.0371

26. F. P. Bretherton, Lamb waves in a nearly isothermal atmosphere. Q. J. R. Meteorol. Soc. 95, 754-757 (1969). doi:10.1002/qj.49709540608

27. R. S. Lindzen, D. Blake, Lamb waves in the presence of realistic distributions of temperature and dissipation. J. Geophys. Res. 77, 2166-2176 (1972). doi:10.1029/JC077i012p02166

28. E. L. Geist, H. M. Fritz, A. B. Rabinovich, Y. Tanioka, Introduction to "global tsunami science: past and future, volume I." Pure Appl. Geophys. 173, 3663-3669 (2016). doi:10.1007/s00024-016-1427-4

29. P. Wessel, J. F. Luis, L. Uieda, R. Scharroo, F. Wobbe, W. H. F. Smith, D. Tian. The generic mapping tools version 6. Geochem. Geophys. Geosyst. 20, 5556-5564 (2019). doi:10.1029/2019GC008515

Acknowledgments: We thank the contributors of each dataset used in the present study. We used ETOPO1 global bathymetry data for simulation (13). Figures were prepared using Generic Mapping Tools (GMT) software (29). 


\section{Funding:}

JSPS KAKENHI JP19K04021 (TS)

JSPS KAKENHI JP19K14818 (TK)

JSPS KAKENHI JP19H02409 (TK, TS)

\section{Author contributions:}

Conceptualization: TK, TS, KN

Methodology: TK, TS

Investigation: $\mathrm{TK}, \mathrm{KN}$

Visualization: TK

Funding acquisition: TK, TS

Writing - original draft: TK

Writing - review \& editing: TK, TS, KN.

Competing interests: Authors declare that they have no competing interests.

Data and materials availability: All data are available on the website of the data contributors.

\section{Supplementary Materials}

Materials and Methods

Figs. S1 to S9

Movies S1 to S2 


\section{Supplementary Materials for}

Global fast-traveling tsunamis by atmospheric pressure waves on the 2022 Tonga eruption

Tatsuya Kubota, Tatsuhiko Saito, Kiwamu Nishida

Correspondence to: kubotatsu@bosai.go.jp

This PDF file includes:

Materials and Methods

Figs. S1 to S9

Captions for Movies S1 to S2

Other Supplementary Materials for this manuscript includes the following:

Movies S1 to S2 
Please note this manuscript is a non-peer reviewed EarthArXiv preprint and has not formally been accepted for publication.

\section{Materials and Methods}

Barograph, ocean-bottom pressure gauge, and coastal tide gauge data

This study used global barograph data recorded by the Global Seismographic Network (GSN) of Incorporated Research Institutions for Seismology (IRIS). The locations of the barometers are indicated by red circles in Fig. 1A. We also used the global tsunami data recorded by the ocean-bottom pressure gauges from the Deep-ocean Assessment and Reporting of Tsunamis (DART) system of the Pacific Marine Environmental Laboratory (PMEL) of the National Oceanic and Atmospheric Administration (NOAA), the Seafloor observation network for earthquakes and tsunamis along the Japan Trench (S-net), and Dense Oceanfloor Network system for Earthquakes and Tsunamis (DONET) of the National Research Institute of Earth Science and Disaster Resilience (NIED). These pressure gauge stations are indicated by the blue inverted triangles in Fig. 1A. We also examined the global tsunami data recorded by the coastal tide gauges retrieved from the Intergovernmental Oceanographic Commission (IOC) (fig. S1). To remove the short-period oceanic noises and long-period tidal fluctuations, we applied a bandpass filter with a passband of 1,800-7,200 s. The filtered time series are shown in Figs. 1B (barometers) and $\mathbf{1 C}$ (pressure gauges), and fig. S1C (tide gauges).

\section{Simulations of atmospheric pressure wave propagation}

To simulate the propagation of atmospheric pressure waves, we solved the twodimensional acoustic wave equations in spherical coordinates:

$$
\begin{aligned}
& \frac{\partial p}{\partial t}+K \frac{1}{R \cos \theta}\left[\frac{\partial v_{\lambda}}{\partial \lambda}+\frac{\partial}{\partial \theta}\left(v_{\theta} \cos \theta\right)\right]=\dot{p}_{S} \\
& \frac{\partial v_{\lambda}}{\partial t}=-\frac{1}{\rho_{\mathrm{a}}} \frac{1}{R \cos \theta} \frac{\partial p}{\partial \lambda} . \\
& \frac{\partial v_{\theta}}{\partial t}=-\frac{1}{\rho_{\mathrm{a}}} \frac{1}{R} \frac{\partial p}{\partial \theta}
\end{aligned}
$$

$R$ is the radius of earth $(=6,378 \mathrm{~km}), \lambda$ and $\theta$ are the longitude and latitude, $p$ is the pressure change, and $\mathbf{v}=\left(v_{\lambda}, v_{\theta}\right)$ is the velocity along the longitude and latitude, respectively. The velocity of the pressure change is then given by $V_{0}=\left(K / \rho_{a}\right)^{0.5}$, where the air density $\rho_{\mathrm{a}}$ and the bulk modulus $K$ are assumed to be homogeneous in space. The velocity was set to $V_{0}=300 \mathrm{~m} / \mathrm{s}$. The function $\dot{p}_{s}$ works as a source of pressure change. We set a point source located at the center of the Hunga Tonga-Hunga Ha'apai, $\mathbf{x}_{0}=\left(175.2^{\circ} \mathrm{E}, 20.3^{\circ} \mathrm{S}\right)$, as

$$
\dot{p}_{s}(\mathbf{x}, t)=p_{0} \dot{\tau}(t) \delta\left(\mathbf{x}-\mathbf{x}_{\mathbf{0}}\right) \Delta S
$$

The function $\dot{\tau}(t)$ is given by

$$
\dot{\tau}(t)=\frac{1}{\sqrt{\pi}} \frac{4}{T_{0}} \exp \left[-\left(\frac{t-t_{c}}{T_{0}}\right)^{2}\right]
$$

where $T_{0}$ is the duration of the pressure change, and $t_{\mathrm{c}}$ is the peak timing of the function (= $\left.0.5 T_{0}\right)$. The small area $\Delta S$ includes the point source. We set the value $p_{0}=20 \mathrm{MPa}\left(2 \times 10^{7} \mathrm{~Pa}\right)$ and the duration as $T_{0}=2,700 \mathrm{~s}$ to simulate the observed pressure change records. Equation (1) was solved by the finite difference scheme with a grid spacing of $\Delta \lambda=\Delta \theta=2 \operatorname{arcmin}(\sim 3.7 \mathrm{~km})$ and a temporal interval of $\Delta t=4 \mathrm{~s}$. 
Please note this manuscript is a non-peer reviewed EarthArXiv preprint and has not formally been accepted for publication.

Modeling of tsunami generation and propagation

After the numerical simulation of the atmospheric pressure wave, we simulated the generation and propagation of the tsunami excited by the atmospheric pressure wave. Similar to the simulation of the atmospheric pressure wave, the following two-dimensional long-wave tsunami equation was solved $(11,12)$ :

$$
\begin{aligned}
& \frac{\partial \eta}{\partial t}+\frac{1}{R \cos \theta}\left[\frac{\partial}{\partial \lambda}\left(h u_{\lambda}\right)+\frac{\partial}{\partial \theta}\left(h u_{\theta} \cos \theta\right)\right]=0 \\
& \frac{\partial u_{\lambda}}{\partial t}=-g_{0} \frac{1}{R \cos \theta} \frac{\partial \eta}{\partial \lambda}-\frac{1}{\rho_{\mathrm{w}}} \frac{1}{R \cos \theta} \frac{\partial p_{\mathrm{atm}}}{\partial \lambda} \\
& \frac{\partial u_{\theta}}{\partial t}=-g_{0} \frac{1}{R} \frac{\partial \eta}{\partial \theta}-\frac{1}{\rho_{\mathrm{w}}} \frac{1}{R} \frac{\partial p_{\mathrm{atm}}}{\partial \theta}
\end{aligned}
$$

where $\eta$ is the sea surface height, $h$ is the seawater depth, $\mathbf{u}=\left(u_{\lambda}, u_{\theta}\right)$ is the velocity, $\rho_{\mathrm{w}}$ is the seawater density $\left(=1,030 \mathrm{~kg} / \mathrm{m}^{3}\right)$, and $g_{0}$ is the gravitational acceleration $\left(=9.8 \mathrm{~m} / \mathrm{s}^{2}\right)$. The external force term, including the atmospheric pressure $p_{\text {atm }}$, drives the tsunami. After the calculation, we calculated the ocean-bottom pressure $p_{\text {bot }}$ by the sum of the pressure changes due to the atmospheric pressure change $p_{\text {atm }}$ and because of the sea-surface height change $p_{\text {eta }}=\rho_{\mathrm{w}} g_{0} \eta$ $(12,14)$, expressed as:

$$
p_{\mathrm{bot}}=p_{\mathrm{atm}}+p_{\mathrm{eta}}
$$

After the calculation, we compared the simulated barograph and ocean-bottom pressure waveforms with the observations (Fig. 2 and fig. S3). Because the present study approximated the spatial dimension of the source of the atmospheric pressure wave as the point source, the arrival time of the simulated waveforms may not appropriately reflect the observed arrivals. Therefore, the traces were uniformly shifted earlier by $t_{\text {shift }}=0.5 T_{0}=1,350 \mathrm{~s}$, so that the wave arrivals coincide with the observation.

Validation of the acoustic wave velocity

The present study assumed an acoustic velocity of $V_{0}=300 \mathrm{~m} / \mathrm{s}$ for the numerical simulation based on barograph observations. We further tested the simulation by assuming various acoustic velocities (fig. S4). Note that the absolute time is arbitrarily shifted in these simulations, so that the arrival times of the simulated waveforms coincide with the observations. The amplitude and relative arrival difference of the pressure and tsunami waves were reasonably explained by all simulations. This indicates that the present analysis could not resolve the propagation speed of the Lamb wave, and the uncertainty range of the Lamb wave velocity falls in $V_{0} \sim 280-320 \mathrm{~m} / \mathrm{s}$. To resolve the propagation velocity of the Lamb waves in greater detail, more careful analysis is necessary.

Investigation of the generation mechanism of the tsunami based on flat-earth simulation

After propagating the pulsive uplift waves at a speed of $300 \mathrm{~m} / \mathrm{s}$, we can confirm the subsequent small sea-surface fluctuation and the propagation of the subsidence waves, the latter which propagates around at the tsunami velocity $c_{0}=\left(g_{0} h_{0}\right)^{0.5}\left(g_{0}\right.$ : gravity acceleration, $9.8 \mathrm{~m} / \mathrm{s}^{2}$, $h_{0}$ : seawater depth (Figs. 2 and 3). To examine the generation mechanism of these subsequent waves, we conducted additional tsunami simulations assuming a constant seawater depth of $h=4$ km (figs. S5 and S6). The simulation results confirmed the uplift wave pulse propagation at a 
Please note this manuscript is a non-peer reviewed EarthArXiv preprint and has not formally been accepted for publication.

velocity of $V_{0}=300 \mathrm{~m} / \mathrm{s}$, but no subsequent small fluctuations were observed (figs. S5 and S6). This result indicates that the origin of these secondary waves was excited by the wave scattering associated with the short-wavelength bathymetry heterogeneity in the Pacific Ocean, such as the Hawaiian Islands, South Pacific Islands, and the Mariana Trench (Fig. 3).

After passing the Lamb-wave pulse and the scattering-originated tsunamis, the propagation of the sea-surface depression can also be confirmed (blue arrows in Fig. 3B), in which its wavefront spreads at the theoretically predicted tsunami velocity. These subsidence wave excitations were confirmed in both simulations with real bathymetry (Figs. 2 and 3 ) and constant seawater depth (figs. S5 and S6). This indicates that the origin of the slow-propagating subsidence wave did not originate from wave scattering. We interpreted this subsidence wave as a result of water volume conservation. When the Lamb wave began to propagate around, the seawater around the volcanic source area was forcibly pushed around, which caused the subsidence of the sea surface at the source to conserve the total water volume. This sea-surface subsidence then collapses due to gravity and propagates around as tsunamis at a velocity of $c_{0}$. The behavior of these leading uplift and subsequent subsidence waves can be visualized more simply by the one-dimensional simulation of the atmospheric wave propagation and the tsunami (Movie S2 and fig. S7). We can confirm that the uplifted wave propagates at the velocity of the Lamb wave $\left(V_{0}\right)$, and the subsidence wave chases it at the velocity of the tsunami $\left(c_{0}\right)$. The behavior of the subsidence wave was also theoretically predicted by ocean wave theory $(14,15)$.

Our simulation results showed that the amplitudes of the forerunning tsunami waves in the ocean-bottom pressure gauges, due to the Lamb wave, had amplitudes of $\sim 3-4 \mathrm{hPa}$ (Fig. 3C), which was slightly higher than the atmospheric pressure disturbance of $\sim 1-2 \mathrm{hPa}$ (Fig. 3A). This amplitude ratio can be explained by ocean wave generation by moving atmospheric pressure $(14,15)$. The amplitude of the ocean-bottom pressure excited by the atmospheric pressure wave moving at a speed of $V_{0}$ is expressed as $p_{\text {obp }}=\left\{1+1 /\left(1-\left(V_{0} / c_{0}\right)^{2}\right)\right\} \times p_{\text {atm }}$ for a plane wave propagation. Considering an average seawater depth of $\sim 4000 \mathrm{~m}$ in the Pacific Ocean, the tsunami propagation velocity is $c_{0} \sim 200 \mathrm{~m} / \mathrm{s}$. Using $V_{0}=300 \mathrm{~m} / \mathrm{s}$, we obtained $p_{\text {atm }} \sim 1.8 p_{\text {atm }}$, which is consistent with the observed amplitude ratio.

Amplitude decay with the propagation distance

As shown in Fig. 4, one should consider some factors on tsunamis arriving after $T_{\text {tsun }}$ to produce the observed waveforms, such as the subsidence tsunami waves compensating the leading uplift waves excited by the Lamb wave (component $2 \mathrm{~A}$ in Fig. 4), the waves related to the atmospheric gravity wave propagating at a velocity close to the tsunami $\left(V_{0} \sim c_{0}\right)$ with the resonance effect (15) (component 2B in Fig. 4), and the tsunamis generated by the seafloor crustal deformation (component $2 \mathrm{C}$ in Fig. 4). If the seafloor is flat, the amplitude of the components $2 \mathrm{~A}$ and $2 \mathrm{C}$ decays with the increase in the propagation distance, in proportion to $r^{-1 / 2}$ ( $r$ : propagation distance). This is because of the geometrical spreading effect of cylindrical waves from the Lamb wave and tsunamis. On the other hand, the amplitude of the wave of component $2 \mathrm{~B}$ increased with travel distance, in which the amplitude of this component is proportional to $r \times p_{\text {atm }}(14,15)$. Considering the geometrical spreading effect of the atmospheric pressure wave, its amplitude increases at a rate proportional to $r^{1 / 2}$. These amplification and decay features can be confirmed in the numerical simulation using the flat ocean earth (figs. S8 and S9). 
Please note this manuscript is a non-peer reviewed EarthArXiv preprint and has not formally been accepted for publication.
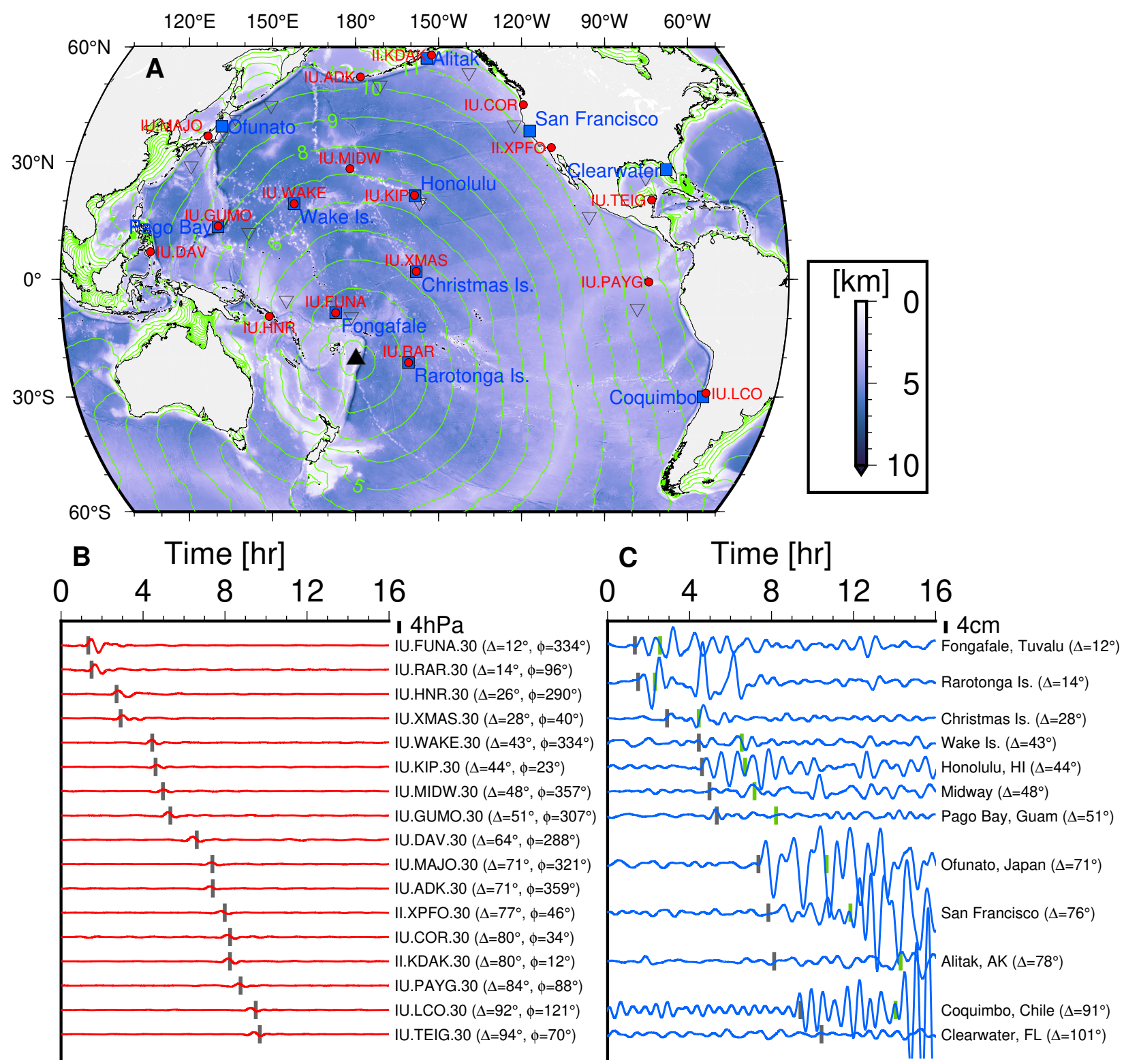

Fig. S1.

Global tide gauge stations and their observed waveforms. The other description of this figure is identical to those in Fig. 1. 


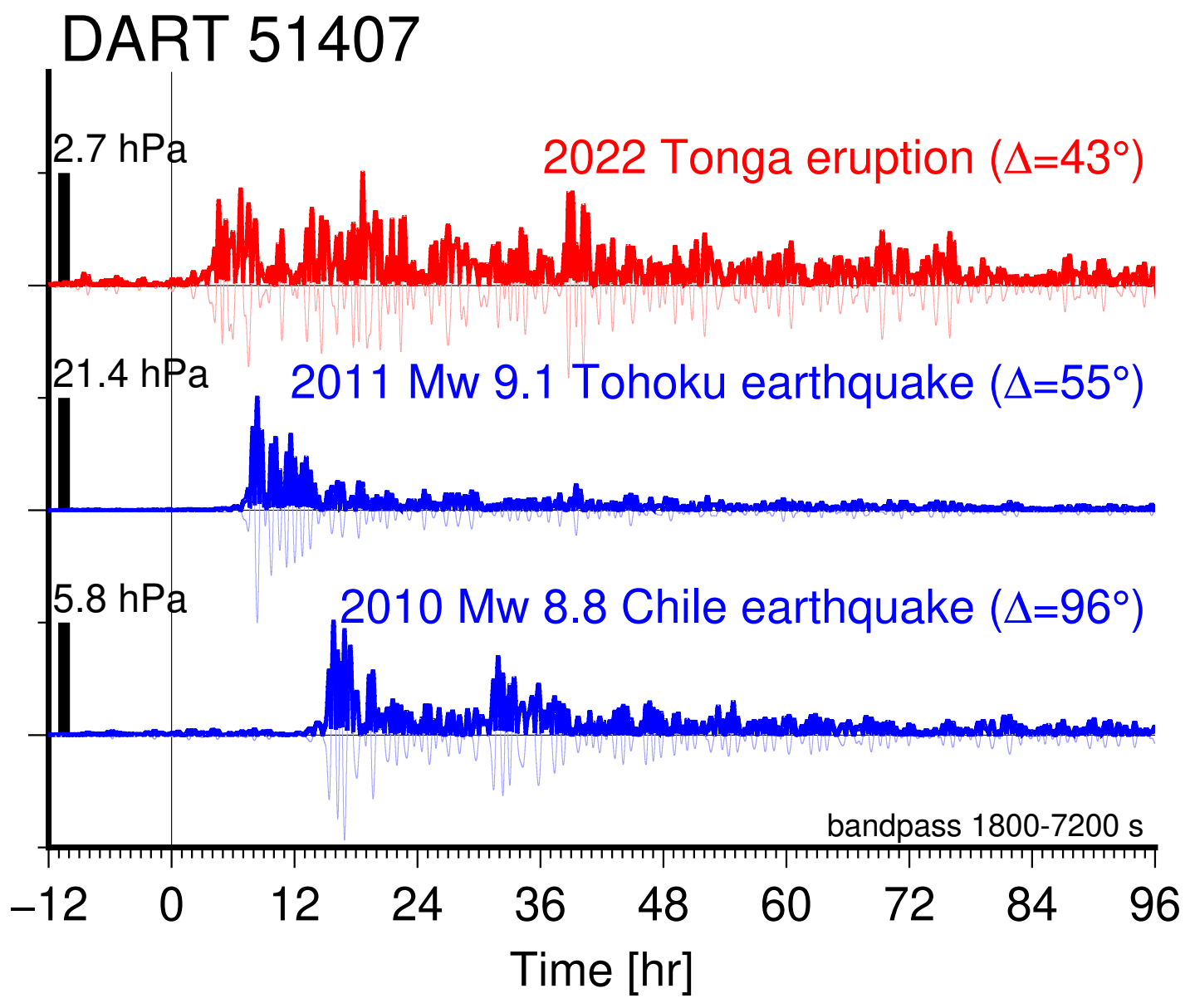

Fig. S2.

A comparison of the ocean-bottom pressure waveforms (thin lines) and their square-rooted mean envelope waveforms (thick lines), at the DART station 51407, between the 2022 Tonga eruption event, the 2011 Tohoku earthquake (Mw 9.1, https:/earthquake.usgs.gov/earthquakes/ eventpage/official20110311054624120_30/executive), the 2010 Chile earthquake (Mw 8.8, https://earthquake.usgs.gov/earthquakes/eventpage/official20100227063411530_30/executive). Note that the vertical scale of each waveform are different. 
Please note this manuscript is a non-peer reviewed EarthArXiv preprint and has not formally been accepted for publication.

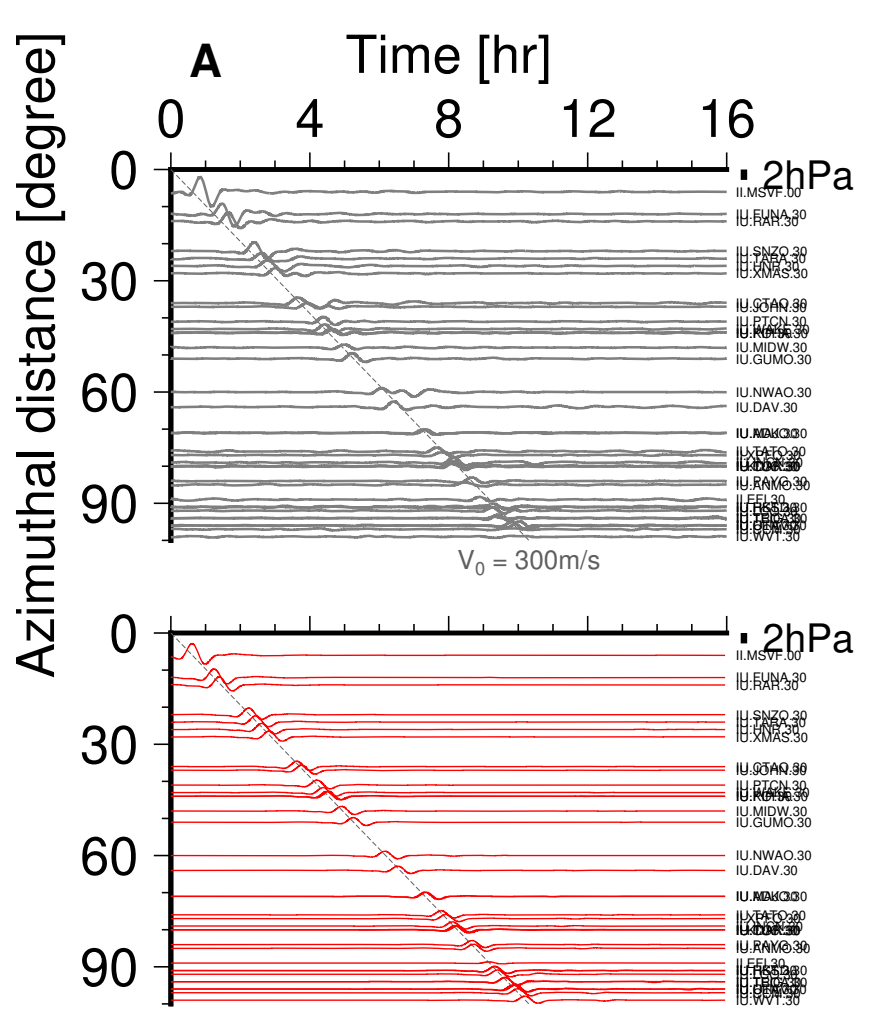

- Obs - Syn $\left(\mathrm{V}_{0}=300 \mathrm{~m} / \mathrm{s}\right)$

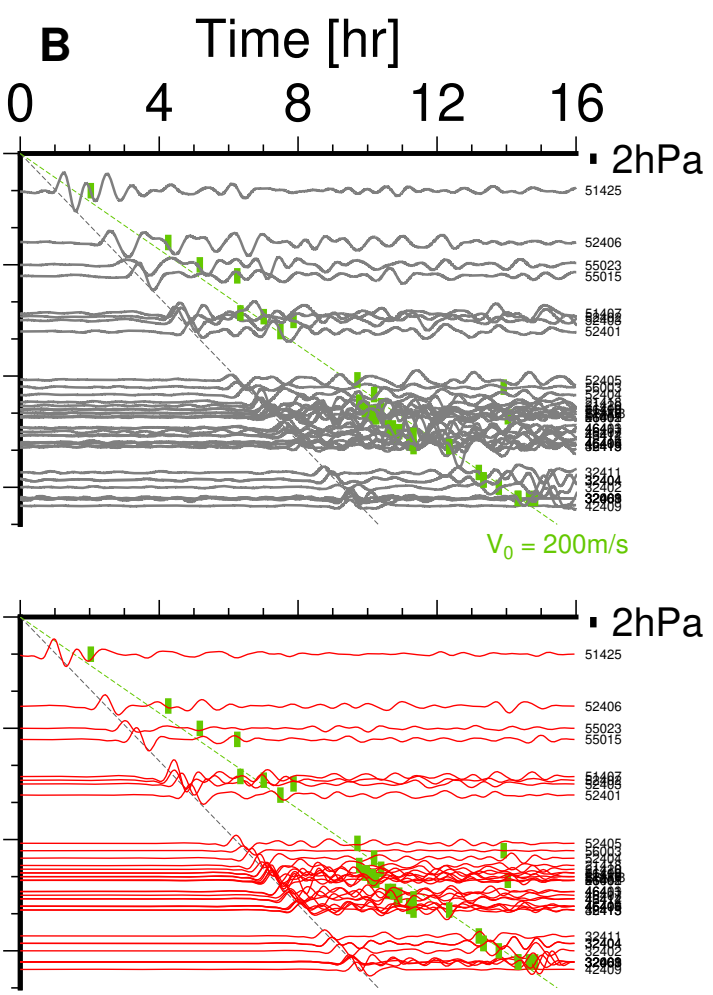

Fig. S3.

Comparisons between the observed and simulated waveforms for the atmospheric pressure velocity of $300 \mathrm{~m} / \mathrm{s}$, in which the traces were aligned by the azimuthal distance. A. Comparison for the barograph waveforms from the GSN of IRIS. B. Comparison for the ocean-bottom pressure waveforms from the DART system of NOAA. Gray and red traces are the observed and simulated waveforms. See the caption of Figs. 1B and 1C for the other description of this figure. 
Please note this manuscript is a non-peer reviewed EarthArXiv preprint and has not formally been accepted for publication.

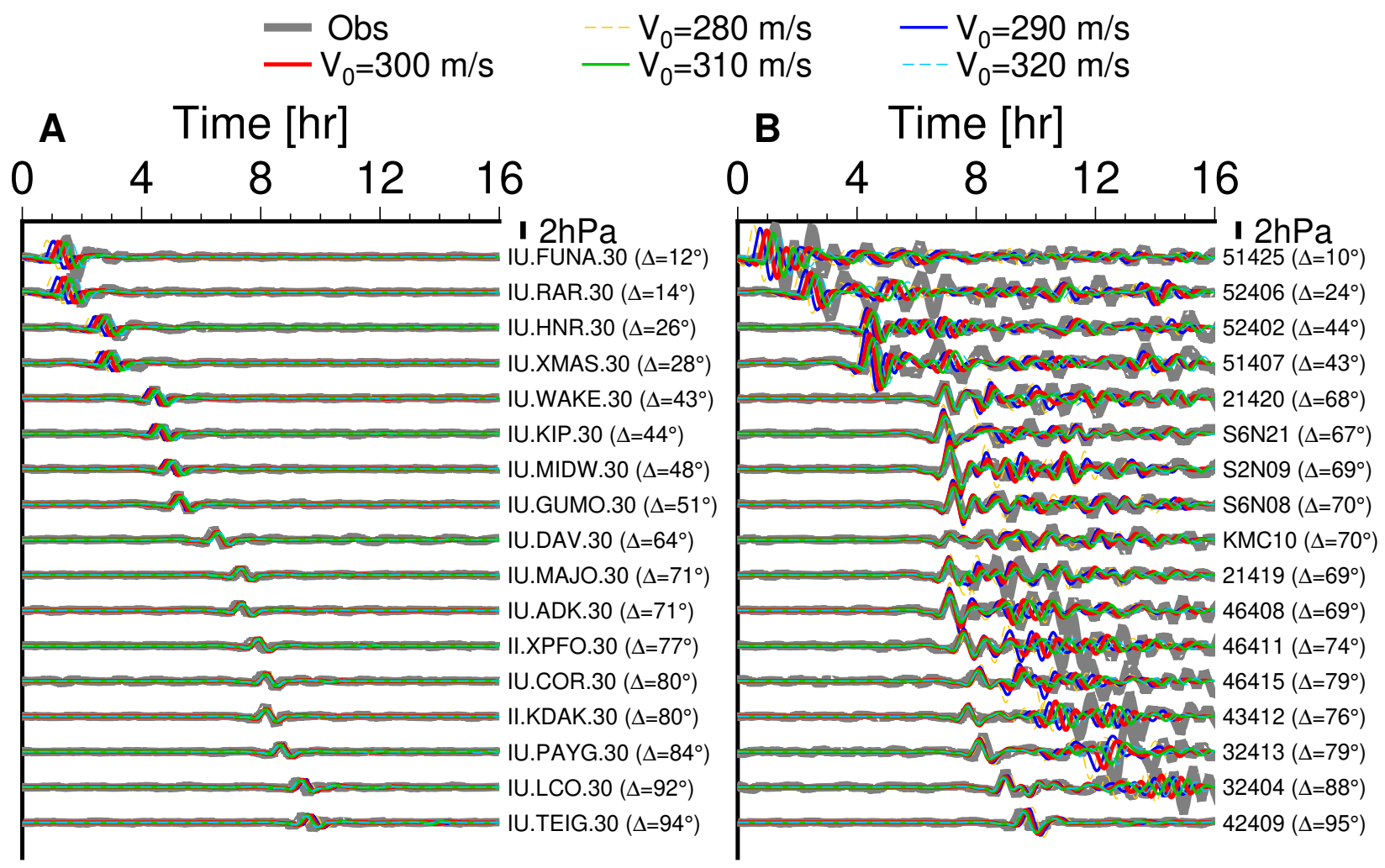

Fig. S4.

Simulation results assuming various acoustic velocities $V_{0}$. See Fig. 2 for detailed explanations of this figure. 
Please note this manuscript is a non-peer reviewed EarthArXiv preprint and has not formally been accepted for publication.

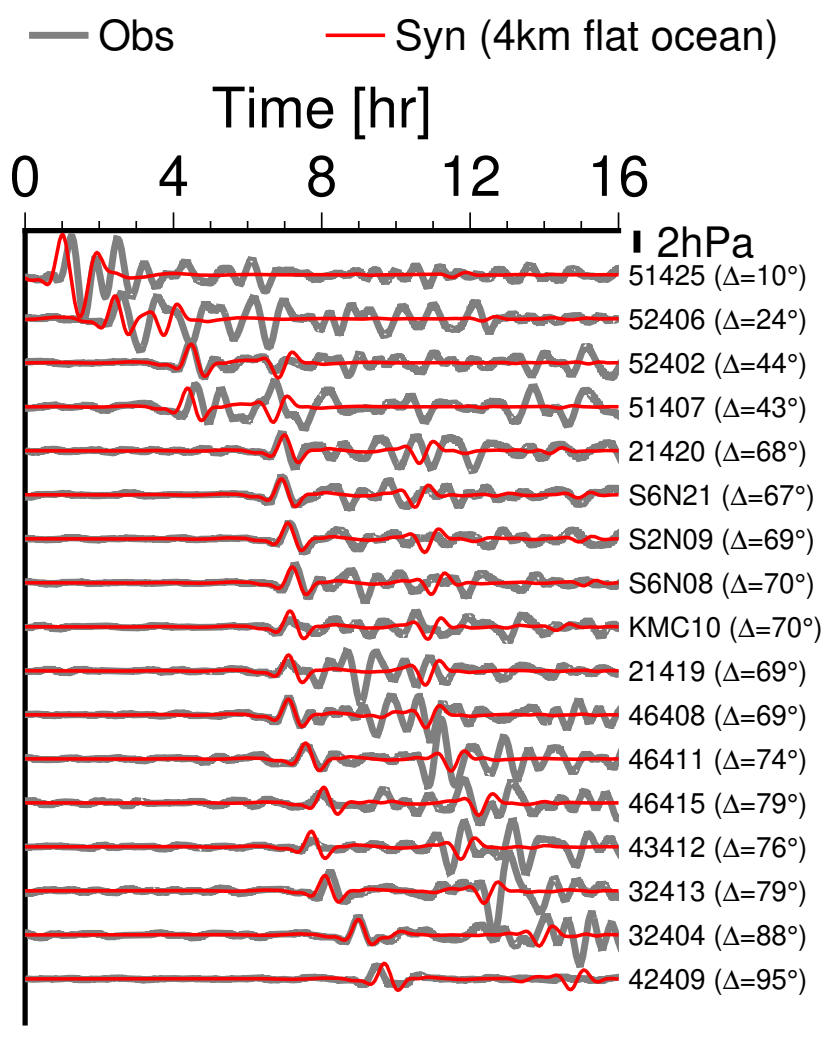

Fig. S5.

Simulated waveforms supposing the constant seawater depth of $h=4 \mathrm{~km}$. 

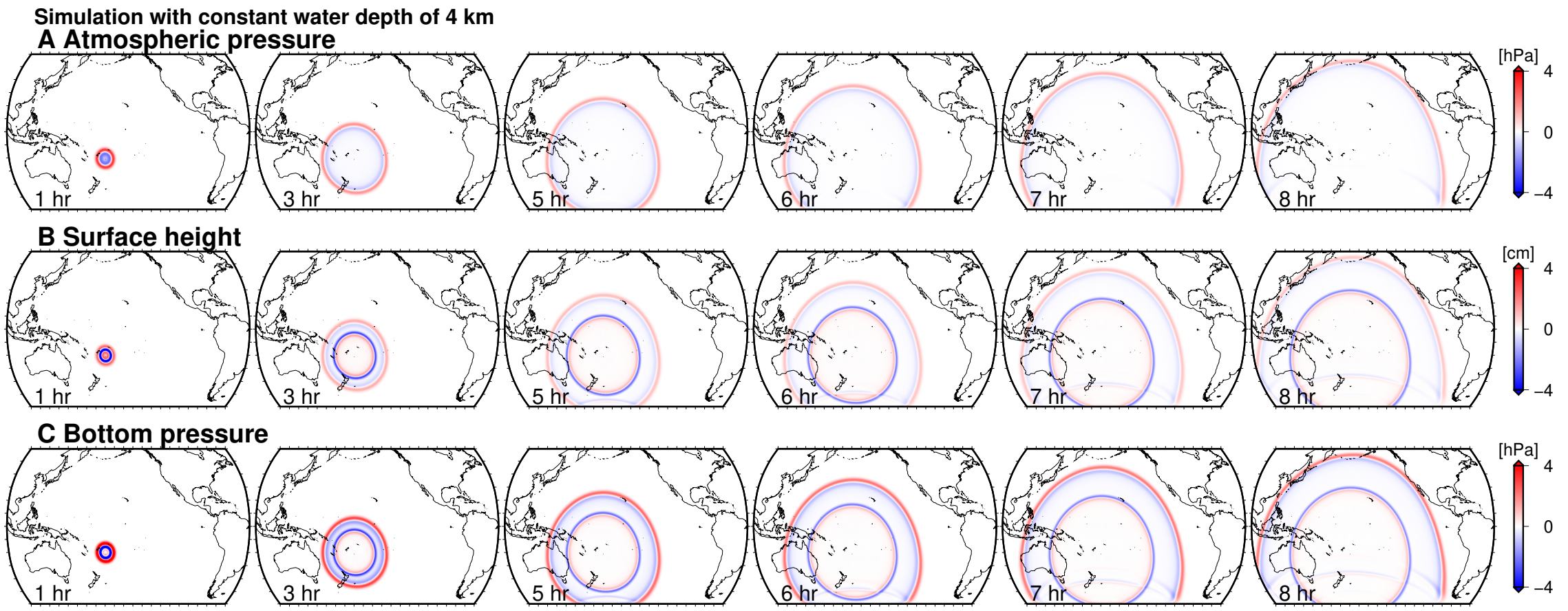

Fig. S6.

Snapshots for the simulation with the constant seawater depth of $4 \mathrm{~km}$. 
Please note this manuscript is a non-peer reviewed EarthArXiv preprint and has not formally been accepted for publication.
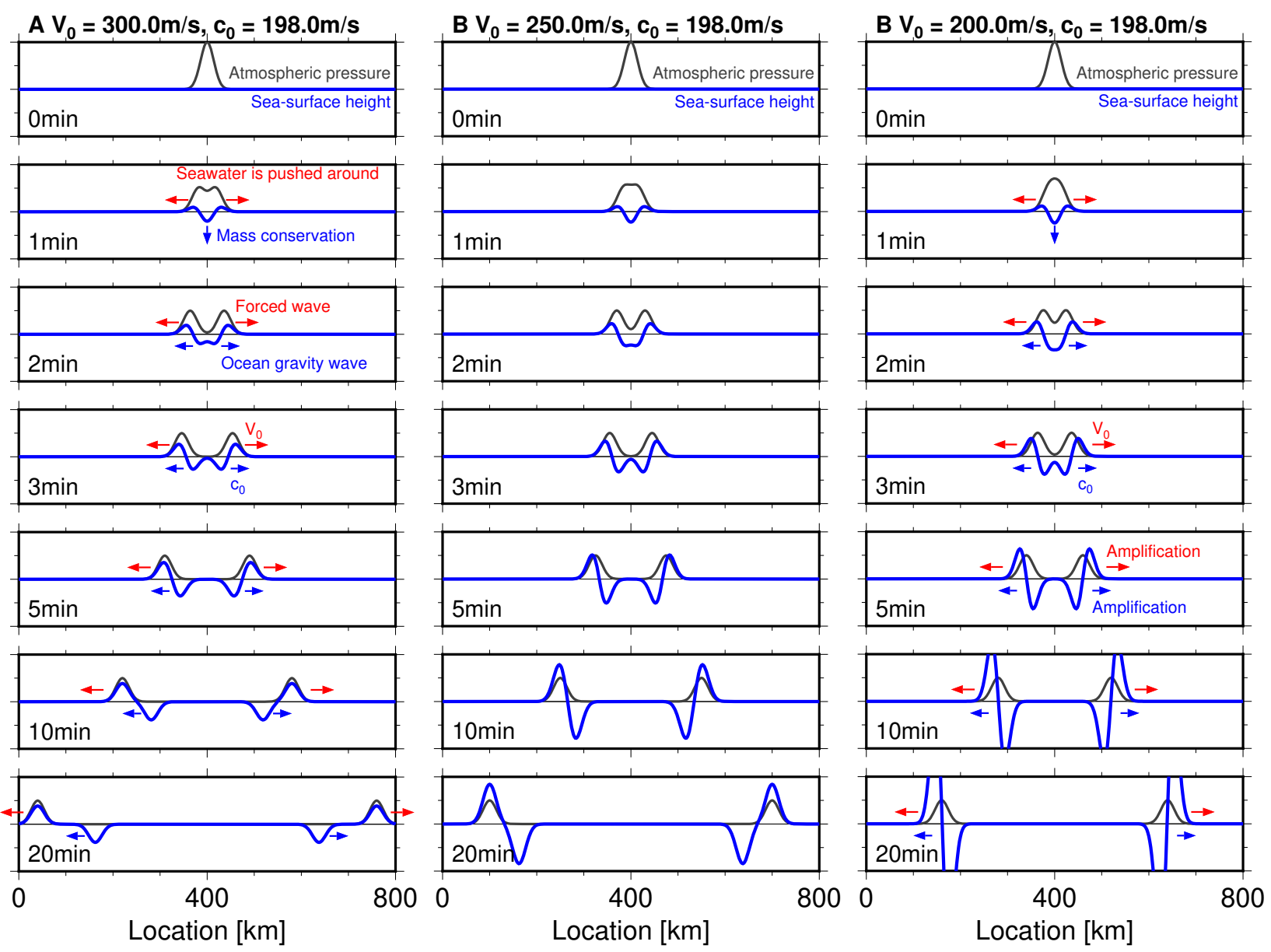

Fig. S7.

The one-dimensional simulation with the constant water depth of $4 \mathrm{~km}$ assuming the moving atmospheric pressure at speeds of A. $V_{0}=300 \mathrm{~m} / \mathrm{s}$, B. $V_{0}=250 \mathrm{~m} / \mathrm{s}$, and C. $V_{0}=200 \mathrm{~m} / \mathrm{s}$. 


\section{A Real bathymetry}

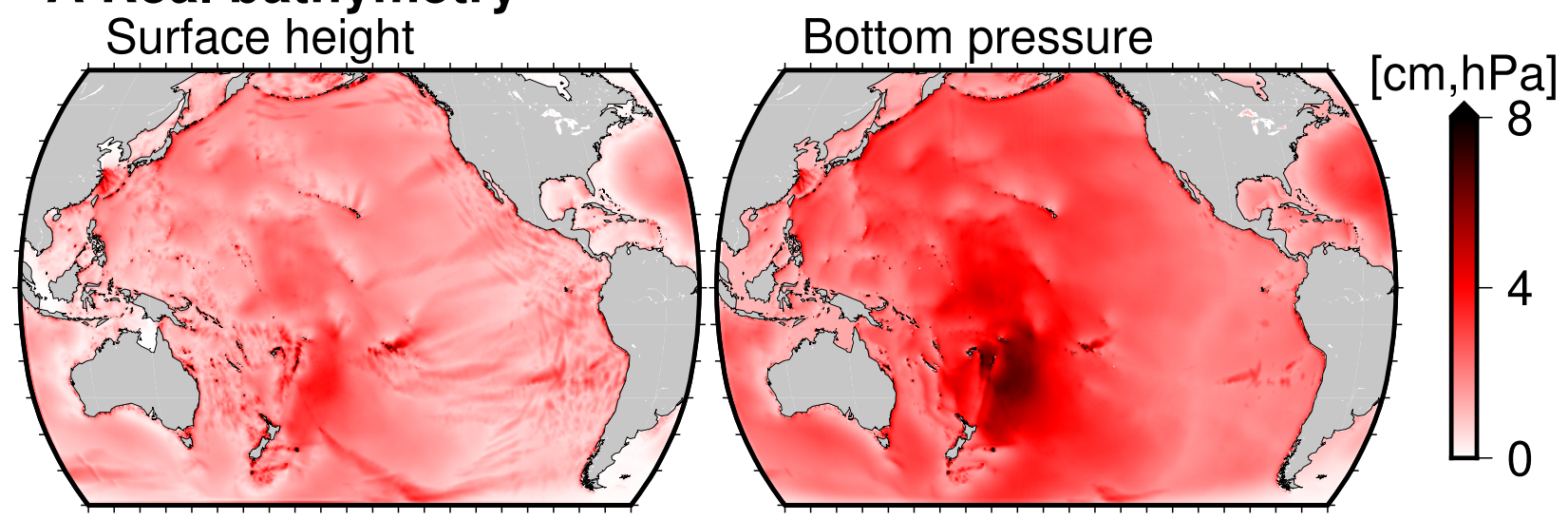

\section{B 4km flat ocean}

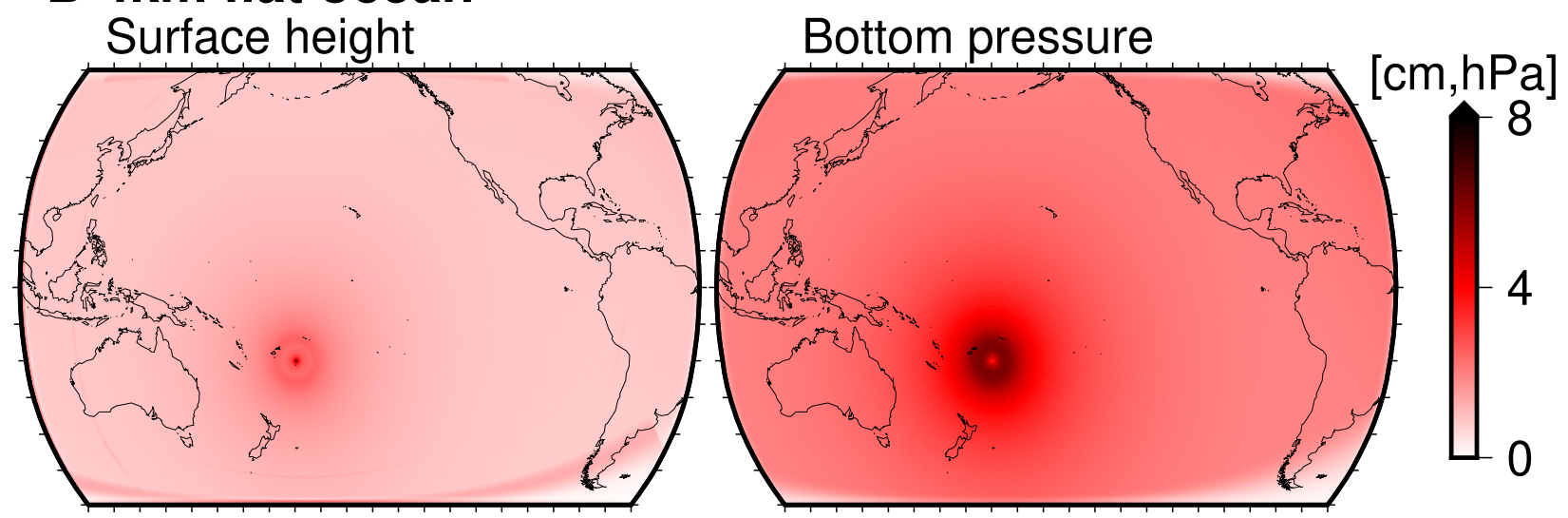

Fig. S8.

Distribution of the maximum amplitude of the simulations with $V_{0}=300 \mathrm{~m} / \mathrm{s}$. A. the real bathymetry and $\mathbf{B}$. constant water depth of $4 \mathrm{~km}$. The left and right panels denote the maximum sea-surface height and the ocean-bottom pressure, respectively. 
Please note this manuscript is a non-peer reviewed EarthArXiv preprint and has not formally been accepted for publication.

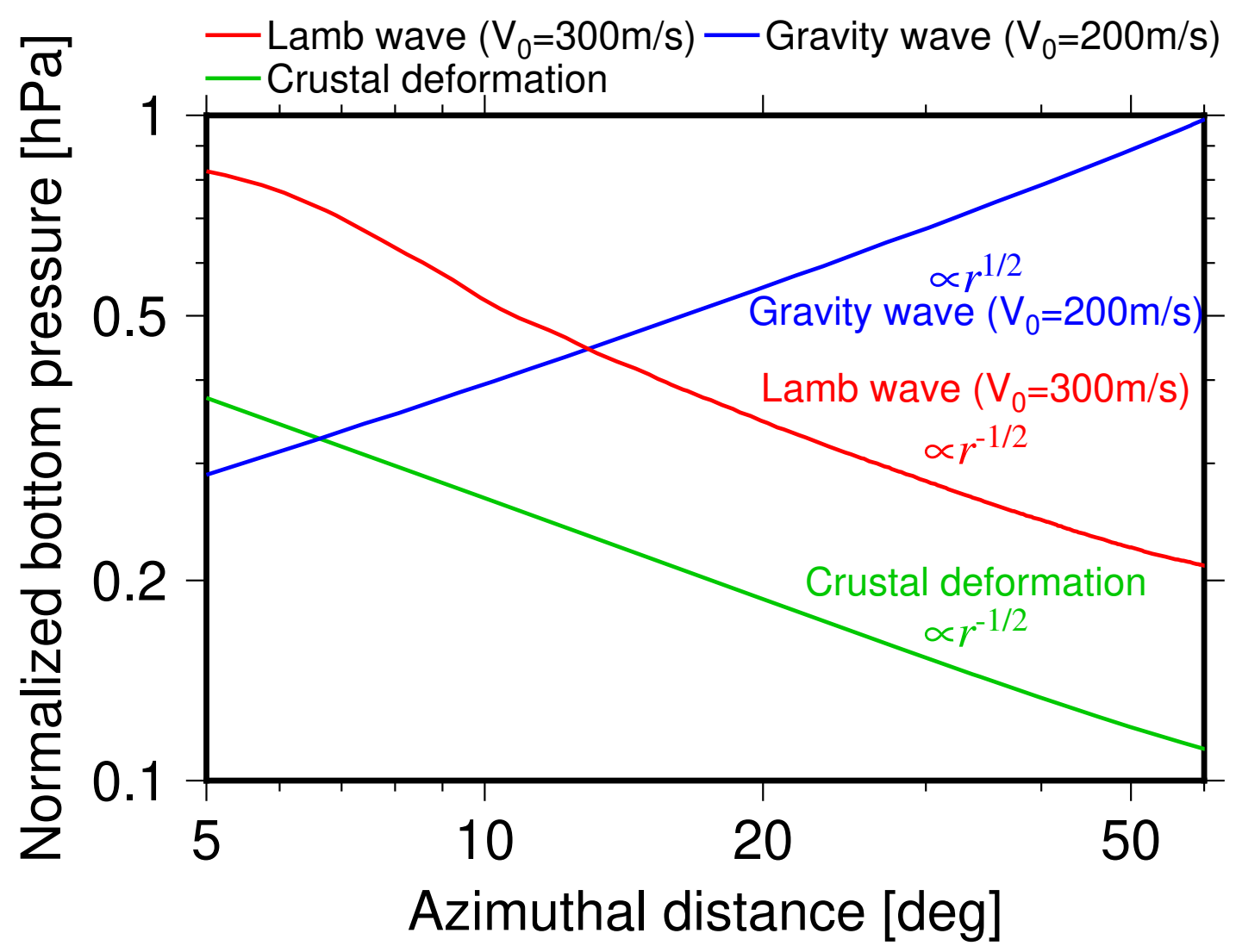

Fig. S9.

Maximum amplitude of the ocean-bottom pressure associated with the propagation distance, based on the simulation with the flat-ocean of $4 \mathrm{~km}$ depth. The amplitude decay at a rate of $\sim r^{-1 / 2}$ can be confirmed for the waves due to the Lamb wave (red) and the crustal deformation at the source region (green) while the amplitude increases at a rate of $\sim r^{1 / 2}$ for the tsunami by slowpropagating atmospheric gravity wave (blue). 


\section{Movie S1.}

Movie showing the propagation of atmospheric pressure, sea surface height, and ocean-bottom pressure.

\section{Movie S2.}

One-dimensional simulation of the atmospheric pressure wave propagation. 